\title{
Students' Attitude towards Using Cooperative Learning for Teaching Reading Comprehension
}

\author{
Nima Farzaneh \\ University of Isfahan, Isfahan, Iran \\ Dariush Nejadansari \\ University of Isfahan, Isfahan, Iran
}

\begin{abstract}
This study project was launched in order to contribute to the studies conducted for investigating the efficiency of different models of reading instruction. The aim of this paper was to investigate students' attitude towards using cooperative language learning techniques for reading instruction. Although cooperative methods are becoming more prevalent in private language schools, there are few studies regarding evaluating the students' attitude towards using cooperative learning for instructing reading comprehension in Iranian context. Evaluation of students' attitude towards the cooperative language learning in this research project was conducted using a survey questionnaire. Analysis of the quantitative questionnaire results showed that the participants generally tend towards supporting the implementation of cooperative strategies in teaching and learning reading comprehension.
\end{abstract}

Index Terms — reading comprehension, cooperative learning, attitude

\section{INTRODUCTION}

Debate over the most effective pedagogical technique to be used in education is a strong challenge now facing the educators in higher levels of education. While some believe in imposing knowledge on students, others suggest that although structures are known within disciplines, it makes sense for students to discover them (Lasley and Ornstein, 2000 p. 20). Today, there seems to be a move towards allowing learners to be more actively involved in the teaching and learning process. To many teachers, one way to make learners shareholders in their learning is to become more of a facilitator of the process of learning, providing guidance for the learners. Scholars have come to the conclusion that one way to improve the intellectual ability of learners is incorporating cooperative learning in teaching. In this instructional method, learners work together as a team to achieve a specific target or objective. However, the incorporation of innovative well-documented methods into the educational context is quite often fraught with difficulties. Learners' perceptions, views, attitudes, and behaviors are major determinants of the success of an instructional program.

Typically in Iranian classrooms at all educational levels a teacher-centered approach seems to be utilized. In such classrooms, the lecturer is typically seen as the repository of knowledge with students passively taking notes, asking very few or no questions. Taking this into account, this study was conducted to investigate students' attitude towards using cooperative learning techniques for teaching English reading comprehension in Iranian private language schools.

\section{RESEARCH QUESTION}

In order to gain a clear understanding of Iranian EFL learners' attitudes about cooperative learning techniques, one overall research question is needed to be answered:

What are the attitudes of Iranian intermediate level English language learners with regard to using cooperative learning techniques in language instruction?

\section{REVIEW OF THE RELATED LITERATURE}

\section{A. Reading Comprehension}

Reading is one of the four basic skills in language learning. Reading provides the learners with a source of comprehensible input and serves to facilitate communicative fluency in other language skills. Furthermore, reading ability has always been viewed as critical to academic success. Reading is a receptive and decoding skill in which the reader receives the writer's message and tries to recreate the writer's message to the extent possible (Chastain, 1988, p. 216). The reading goal is to read for meaning or to recreate the writer's meaning. By definition, reading involves comprehension. When readers do not comprehend, they are not reading (ibid, p. 217).

Scholars of reading believe that reading is a dynamic process which is varied from reader to reader and from text to text and that the key factor in understanding this process is the interaction between readers and text variables. Therefore, according to Alderson (2000), reading-related research has been commonly divided into two different factors: 
the reader and the text. Reader's knowledge constitutes one highly significant reader variable. The nature of the knowledge brought to the reading process by the reader affects the way the text is processed and understood to a great extent. Moreover, the reader's linguistic knowledge, especially, vocabulary size and metalingustic knowledge are important factors. Schema theory has been developed in order to determine to what extend readers' knowledge affects what they understand. In addition, according to Bernhardt and Kamil (1995), the transfer of reading ability from L1 to L2 must be considered in this regard. The reader's motivation for reading constitutes another significant reader variable. When it comes to text variables, the major variable is known to be the language of the text. Many aspects of text, including text content, text type, text organization, and sentence structures might help facilitate or complicate the reading process.

Theories and models of reading have undergone dramatic change in recent years. Reading is no longer seen as a primarily receptive process from text to reader. Instead, reading is regarded as an interactive process between the reader and the text (Adams, 1990). A taxonomy of different types of comprehension is developed based on the ideas of Pearson and Johnson (1972) and Nuttall (1996). This taxonomy includes six different types of comprehensions which are thought to help students to become interactive readers. They are: literal comprehension, reorganization, inference, prediction, evaluation, and personal response.

\section{B. What Is Cooperative Learning?}

A survey of research and trends in cooperative language learning reveals that the incorporation of cooperative learning into educational programs was first initiated in content areas such as social studies, science, and mathematics. However, after these innovative methods proved to be effective in educational research, the researchers in the field of language teaching and learning turned their attention to this approach. Cooperative learning is a teaching approach in which learners of diverse abilities, talents and backgrounds work together in small groups to attain a common goal. "Cooperative learning is group learning activity organized so that learning is dependent on the socially structured exchange of information between learners in groups and in which each learner is held accountable for his or her own learning and is motivated to increase the learning of others" (Olsen and Kagan, 1992:8, as cited in Richards and Rodgers, 2001). There have been many studies that have been conducted that have placed a high value on cooperative learning. Cooperative learning aims at learner-centered learning and claims to increase the level of understanding and reasoning, develop critical thinking, and increase the accuracy of long - term retention (Koppenhaver \& Shrader, 2003). In addition, Johnson, Johnson, and Stanne (2000) suggest that cooperative learning be absorbed in the mainstream of educational practice because it is a theoretically-based approach which has been proved to be highly effective in enhancing student learning and improving social relations compared to other non-cooperative instructional methods, and there are plenty of cooperative learning techniques available to be employed by teachers. It is further believed that active participation in the learning experience will result in an improvement in academic performance. In addition, in this approach an "atmosphere of achievement" is created because learners will work on the assigned task until all members of the group achieve the goal of successfully understanding and completing the assignment (Panitz, 1996). As Bourner (1997) states "teaching methods are not an end in themselves, but a means to an end, they are the vehicle (s) we use to lead our students to particular learning outcomes."

The cooperative learning approach encompasses a variety of instructional strategies, including Jigsaw Procedure, Group Investigation (GI), Three-Step Interview, Student-Team-Achievement-Divisions (STAD), Academic Controversy (AC), and Teams-Games-Tournaments (TGT), to mention but a few. Johnson, Johnson, and Stanne (2000) report that in the literature the following methods have received the most attention:

TABLE 2.1:

MODERn Methods OF CL (ADOPTED FROM JOHNSON, JOHNSON, \& STANNE, 2000)

\begin{tabular}{|l|l|l|}
\hline Reseacher-Developer & Date & Method \\
\hline Johnson \& Johnson & Mid 1970s & Learning Together (LT) \\
\hline DeVries \& Edwards & Early 1970s & Teams-Games-Tournaments (TGT) \\
\hline Sharan \& Sharan & Mid 1970s & Group Investigation (GI) \\
\hline Johnson \& Johnson & Mid 1970s & Constructive Controversy \\
\hline Aronson \& Associates & Late 1970s & Jigsaw Procedure \\
\hline Slavin \& Associates & Late 1970s & Student Teams Achievement Divisions (STAD) \\
\hline Cohen & Early 1980s & Complex Instruction \\
\hline Slavin \& Associates & Early 1980s & Team Assisted Instruction (TAI) \\
\hline Kagan & Mid 1980s & Cooperative Learning structures \\
\hline Stevens, Slavin \& Associates & Late 1980s & Cooperative Integrated Reading \& Composition (CIRC) \\
\hline Kagan & Early 1990s & Three-Step Interview \\
\hline Kagan & Late 1980s & Inside-Outside Circle \\
\hline
\end{tabular}

James A. Duplass (2006) believes that cooperative learning incorporates the following eight basic features:

- Teacher supervision: the instructor should always monitor group activity in order to make sure that learners are not veering too far off the assigned task. Also, the instructor should also be available for answering questions raised by the learners and guiding them through the discussion.

- Heterogeneous groups: groups of diverse levels of ability and from different backgrounds should be created. 
- Positive interdependence: to achieve positive interdependence, the group should work towards a reward or final learning objective.

- Face-to-face interaction: the teacher should encourage the learners to use verbal and nonverbal communication to explain learning materials to each other or deal with problems encountered.

- Individual accountability: learners are assigned specific roles in the group to ensure they are accountable for completing their tasks. In addition, each member of the group should assist the whole group in meeting the learning outcome.

- Social skills: cooperative learning promotes social skills such as speaking in an appropriate manner, being respectful, and wisely utilizing the time allocated to a task.

- Group processing: learners should reflect on the way the group functioned during learning activities.

- Evaluation: assessment can take the form of both individual and group assessment.

Review of related literature indicates that two main theories guide the studies related to cooperative learning. The first theory is constructivism which emphasizes the need for the learner to actively participate in the teaching-learning process. According to Hein (1991), the term constructivism refers to the idea that learners construct knowledge for themselves individually and socially as they learn. The second is the theory of motivation which suggests that it is not only the instructional style that influences a students' academic performance, but how much that individual wants to succeed. Woolfolk (2006) defines motivation as an internal state that provokes, guides and sustains behaviour. Motivation can either be intrinsic (internal stimuli) or extrinsic (external stimuli). At times it might be necessary to provide students with incentives for accomplishing a task, but ideally we should attempt to nurture our students to be intrinsically motivated.

\section{Importance of Students' Attitude}

Researchers constantly maintain that reading instructions that emphasize active, learner-centered approaches prove to be effective. According to Ajzen and Fishbein's (1980) theory of reasoned action, "attitudes are a function of beliefs" (p. 7). Based on this theory, believing that performing a task will result in mainly positive outcomes results in taking a favorable attitude towards the task. On the other hand, mistrust of the success of performing a task will lead to taking an unfavorable attitude. Therefore, if participants believe that, for example, cooperative methods will have a significant effect on their reading comprehension, then this method will be to their benefit. Attitudes, once formed, can shape the way students think, understand, feel, and behave. "Attitudes and beliefs are a subset of a group of constructs that name, define, and describe the structure and content of mental states that are thought to drive a person's actions" (Richardson, 1996, p. 102, as cited in Rimm-Kaufman \& Sawyer, 2004). The evaluation of students' attitude may provide new insights into the way these attitudes may hinder or facilitate learning.

\section{Methodology}

This section of the study outlines the methodology. In the following sections, information about the participants of the study, research design, the instrument used and the procedure for the study is presented.

\section{A. Participants}

The participant pool for the study was 52 intermediate EFL learners, 16 male and 36 female, attending Gouyesh Language School in Gachsaran in 2013.

\section{B. Design of the Study}

In this study a descriptive, survey-based design is employed. To determine the views of intermediate level students towards cooperative learning strategies, a survey questionnaire was used.

\section{Instrument}

As mentioned before, a survey questionnaire was distributed among the participants in order to determine their views about employing cooperative techniques for instructing reading comprehension. The questionnaire survey technique is a very effective tool since it enables large scale numerical data to be obtained over a short period of time. It can also be easily administered. In this particular study, the researcher wanted to gain numerical data to indicate students' views on cooperative learning methods.

The uni-dimensional questionnaire used in the study was developed by McLeish (2009) and had 12 items (See Appendix B). For the purpose of analyzing the gathered data, the respondents were allowed to rate each item on a scale of options which were numerically coded as 1 (strongly disagree); 2 (disagree); 3 (neutral); 4 (agree); 5 (strongly agree). Needless to say, the reliability and validity of the questionnaire were already determined by the afore-mentioned researcher.

\section{Procedures}

This section discusses the procedure for data collection. 54 intermediate EFL learners, 16 male and 38 female, attending Gouyesh Language School in Gachsaran, agreed to take part in this research project. The participants had already been instructed reading comprehension by the researcher using cooperative language learning strategy called 
Jigsaw Procedure for a period of five weeks. To determine the views of the learners towards cooperative strategies, the survey questionnaire was distributed among them after they had received the treatment. Finally, the results of the survey were analyzed to identify the learners' attitude towards cooperative techniques.

\section{DAta Analysis \& Results}

In this section the process of data analysis and the results achieved are presented. As mentioned in previous sections, the data collected for this study was gathered through the distribution of a questionnaire among 52 intermediate EFL learners, drawn from the available pool of intermediate-level English language learners at Gouyesh Language School in Gachsaran. The data obtained from the survey were analyzed and interpreted using Statistical Packages for the Social Sciences (SPSS) version 19. Figure 1 tabulates the results. Section V consists of two parts. While the first subsection of the data analysis aims to interpret the results of per-statement analysis, the second subsection aims to interpret the data at an overall analysis level.

\section{A. The Results of Per-statement Analysis}

The results of per-statement analysis, demonstrated in Figure 1, will be discussed in detail in this part.

Item 1: I willingly participate in cooperative learning activities.

On whether or not the learners willingly participate in cooperative learning activities, the mean value is 4.42 . So, it can be said that the vast majority of the respondents believe that they are perfectly willing to participate in such learning activities. This is the statement students agree with the most.

Item 2: When I work with other students I achieve more than when I work alone.

As noted in the literature, cooperative learning techniques claim to result in higher educational achievement. The second item of the survey questionnaire addresses this issue. The mean value for this item is 3.96. This indicates that participants support the idea that when they work with other students they achieve more than when they work alone.

Item 3: Cooperative learning can improve my attitude towards work.

This item asks the respondents' opinion on whether cooperative learning can improve the attitude towards work. The approximate mean value for this item is 4.00 . Therefore, we can conclude that the learners almost agree that cooperative learning can improve their attitude towards work and this may result in mostly positive outcomes.

Item 4: Cooperative learning helps me to socialize more.

Cooperative learning is a teaching approach in which learners of diverse abilities, talents and backgrounds work together in small groups to attain a common goal. Proponents of this approach believe that individual accountability needs to be combined with teamwork in order to help learners acquire both knowledge and social skills. As indicated in Figure 1, the mean score of 4.39 indicates that the participants support the statement that cooperative learning enhances socialization.

Item 5: Cooperative learning enhances good working relationships among students.

One of the basic principles fundamental to cooperative learning is positive interdependence. This requires creating an atmosphere in which learners feel that they depend on each other in order to complete the assigned task. Figure 1 shows that learners believe that more positive and supportive relationships with peers can be one of the advantages of using cooperative techniques in teaching and learning context. The mean value for this item is 4.21 .

Item 6: Cooperative learning enhances class participation.

On whether or not cooperative learning enhances class participation, the participants completely agree with the statement. The mean value for this item is 4.35 which is one of the highest mean scores in the questionnaire.

Item 7: Creativity is facilitated in the group setting.

Participants tended towards the opinion that creativity is facilitated in the group setting, as evidenced by Figure 1. The mean score for item 7 is 3.85 which is one of the lowest scores in the questionnaire.

Item 8: Group activities make the learning experience easier.

Concerning the issue of whether group activities make the learning experience easier, participants agree on the statement. The mean score for this item reached over 4.00.

Item 9: I learn to work with students who are different from me.

As mentioned before, in cooperative learning, to achieve a common goal, students of various talents, abilities, and backgrounds need to work together. Item 9 of the questionnaire addresses this issue. The mean score of 4.17 indicates that students agree with this item.

Item 10: I enjoy the material more when I work with other students.

To evaluate the extent to which learners enjoy the material when they work with other learners, the respondents' answers to item 10 of the questionnaire were analyzed. Although the mean value for this item is one of the lowest scores, the mean value of 3.82 indicates that participants generally tend to support this statement.

Item 11: My work is better organized when I am in a group.

The statement regarding whether the learners' work is better organized when they are in a group scored the lowest mean in the questionnaire. The mean value for this item is 3.46. This is probably because, in some cases, one or two team members have to do all the work and the other members simply go along for the ride, and in others cases, dominant students desire for a good grade and as a result stifle their teammates' efforts to contribute. 


\section{Item 12: I prefer that my teachers use more group activities / assignments.}

Finally, Figure 1 shows that, like item 7, the participants tend towards the opinion that more group activities and assignments be used in teaching and learning context.

\section{B. The Overall Results}

Figure 1 indicates that the three statements students agree with the most are attitude items 1, 4, and 6 with mean values of 4.42, 4.39, and 4.35. These items investigate learners' attitude regarding willingly participating in cooperative learning activities, cooperative learning helping learners to socialize more and cooperative learning enhancing class participation, respectively. On the other hand, attitude item 11 is agreed with the least with mean value of 3.46. This item asks participants whether their work is better or less organized when they work in a group. The overall results demonstrate that the respondents generally tend towards supporting the implementation of cooperative strategies in teaching and learning context.

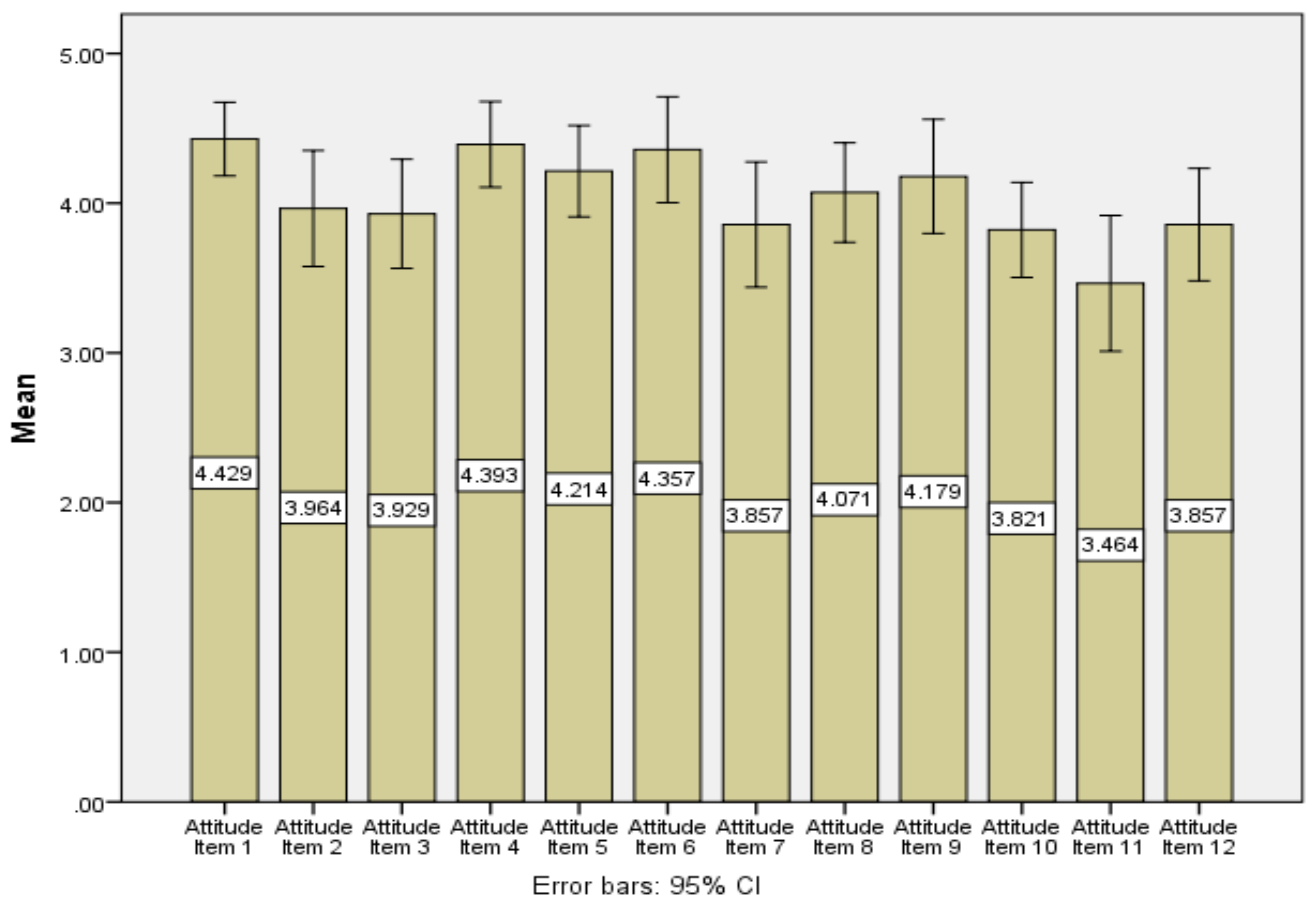

Figure 1: Students’ Attitude towards Cooperative Language Learning

\section{DisCUSSION \& CONCLUSION}

The results of this study indicate that the participants hold generally a positive view of the implementation of cooperative strategies in teaching and learning context. This is probably because when students work in groups they feel that they can depend on others for help and this gives them the confidence to solve problems and enjoy learning. Positive attitude towards cooperative approaches may indirectly change the learners' attitude towards language learning and encourage their interest.

Based on findings of the study, it is necessary that teachers use cooperative learning approach side by side with noncooperative learning approaches. It is worth mentioning that successful implementation of cooperative learning techniques requires structurally planned teaching and learning activities. Also, it is recommended that this approach be employed for skills like reading comprehension because cooperative learning collects suggestions and ideas from different group members and contributes the concepts become easily clear. Moreover, this approach can also be used for the instruction in other skills such as listening, speaking, and writing. In addition, the literature suggests that additional reasons may motivate the instructors to use cooperative learning techniques. For instance, "the ability to work with others within a group and to develop interpersonal skills" might be an acceptable justification for implementing cooperative learning strategies (Abu and Flowers, 1997). Increased interaction in English and easy management of large classes may be other motivating factors for employing cooperative learning approach.

\section{ApPendix A. The ATtitude QuestionnAire}

\section{Students' Attitude towards Cooperative Learning}

Respondent Number: 
Dear respondent,

This questionnaire is designed to investigate students' attitude toward Cooperative Learning. The researcher really appreciates your cooperation and participation.

INSTRUCTION: To respond to this questionnaire, please put a check mark $(\sqrt{ })$ in the appropriate box to indicate your level of agreement or disagreement with the statements:

1 (strongly disagree); 2 (disagree); 3 (neutral); 4 (agree); and 5 (strongly agree)

\begin{tabular}{|c|c|c|c|c|c|c|}
\hline No. & Statement & 1 & 2 & 3 & 4 & 5 \\
\hline 1 & I willingly participate in cooperative learning activities. & & & & & \\
\hline 2 & When I work with other students I achieve more than when I work alone. & & & & & \\
\hline 3 & Cooperative learning can improve my attitude towards work. & & & & & \\
\hline 4 & Cooperative learning helps me to socialize more. & & & & & \\
\hline 5 & Cooperative learning enhances good working relationships among students. & & & & & \\
\hline 6 & Cooperative learning enhances class participation. & & & & & \\
\hline 7 & Creativity is facilitated in the group setting. & & & & & \\
\hline 8 & Group activities make the learning experience easier. & & & & & \\
\hline 9 & I learn to work with students who are different from me. & & & & & \\
\hline 10 & I enjoy the material more when I work with other students. & & & & & \\
\hline 11 & My work is better organized when I am in a group. & & & & & \\
\hline 12 & I prefer that my teachers use more group activities / assignments. & & & & & \\
\hline
\end{tabular}

\section{REFERENCES}

[1] Abu Abu, R., \& Flowers, J. (1997). The effects of cooperative learning methods on achievement, retention and attitude of home economic students in North Carolina. Journal of Vocation and Technical Education 13.2. http://scholar.lib.vt.edu/ejournals/JVTE/v13n2/Abu.html. (retrieved 15/8/2013).

[2] Adams, M.J. (1990). Beginning to read: Thinking and learning about print. Cambridge, MA: MIT Press.

[3] Ajzen, I. \& M. Fishbein (1980). Understanding attitudes and predicting social behaviour (2 vols.). Englewood Cliffs, NJ: Prentice-Hall.

[4] Alderson, J. C. (2000). Assessing reading. Cambridge: Cambridge University Press.

[5] Bernhardt, E. B., \& Kamil, M. L. (1995). Interpreting relationships between L1 and L2 reading: Consolidating the linguistic threshold and the linguistic interdependence hypothesis. Applied Linguistics 16.1, 15 -34.

[6] Bourner, T. (1997). Teaching methods for learning outcomes. Education and Training, 93, 9, 344 -348.

[7] Chastain, k. (1988). Developing second language skills: Theory and practice ( ${ }^{\text {rd }}$ ed.). San Diego: Harcourt Brace Jovanovich.

[8] Duplass, J. (2006). Middle and High School Teaching: Methods, Standards, and Best Practices. Boston: Houghton Mifflin Company.

[9] Hein, G. (1991). Constructivist Learning Theory. CECA (International Committee of Museum Educators) Conference Jerusalem Israel, 15-22 October 1991. http://www.exploratorium.edu/ifi/resources/constructivistlearning.Html. (accessed 21/5/2010).

[10] Johnson, D. W., Johnson, R. T., \& Stanne, B. (2000). Cooperative learning methods: A meta-analysis. University of Minnesota, Minneapolis, Minnesota. http://www.tablelearning.com/uploads/File/EXHIBIT-B.pdf. (retrieved 21/11/2012).

[11] Koppenhaver, G.D. and Shrader, C.B. (2003). Structuring the Classrooms for Performance: Cooperative Learning With Instructor-Assigned Teams. Decision Sciences Journal of Innovative Education. 1, 1, 1-21.

[12] Lasley, T. and Ornstein, A. (2000). Strategies for Effective Teaching 4th Ed. McGraw Hill: New York.

[13] Nuttall, C. (1996). Teaching reading skills in a foreign language. Oxford: Heinemann English Language Teaching.

[14] Panitz, T. (1996). A definition of collaborative versus cooperative learning, Deliberations [Online].Available: http://www.londonmet.ac.uk/deliberations/collaborative-learning/panitz-paper.cfm.

[15] Pearson, P. D. \& Johnson, D. D. (1972). Teaching reading comprehension. New York: Holt, Rinehart \& Winston.

[16] Richards, J. C. \& Rodgers, T. (2001). Approaches and methods in language teaching (2 $2^{\text {nd }}$ ed.) Cambridge, UK: Cambridge University Press.

[17] Rimm-Kaufman, S. E. \& Sawyer, B. E. (2004). Primary-grade teachers' self-efficacy beliefs, attitudes toward teaching, and discipline and teaching practice priorities in relation to the responsive classroom approach. The Elementary School Journal, 104, 321-341.

[18] Woolfolk, A. (2007) Educational psychology (10th Ed.) Pearson: New York.

Nima Farzaneh is an M.A. graduate in TEFL, English Department at University of Isfahan, Iran. He received his B.A. in English Language and Literature from Shiraz University, Iran. He teaches and translates English at different institutes. His areas of interest include materials evaluation, applied linguistics, teaching language skills and translation studies.

Dariush Nejadansari is an assistant professor at Isfahan University, Iran. He has been teaching different courses in second language acquisition at MA and $\mathrm{PhD}$ level. He has got his MA in teaching English as a foreign Language from Tarbiat Modarres University, Tehran, Iran and PhD in TEFL from Allame Tabatabaei University, Tehrn, Iran. His area of interest is different is sues in SLA. 